\title{
CEREBRAL INFARCT IN CHILDREN AGED ZERO TO FIFTEEN YEARS
}

\author{
Thelma Ribeiro Noce1, Soraia Ramos Cabete Fábio1, José Ibiapina Siqueira Neto², \\ Antônio Carlos dos Santos ${ }^{1}$, Carolina Araújo Rodrigues Funayama ${ }^{1}$
}

\begin{abstract}
Cerebral infarcts in children present peculiar characteristics either due to their diversity of causes or due to the unknown nature of the causes. The etiologies of cerebral infarct were reviewed in children from zero to 15 years old, attended at a tertiary hospital, in Ribeirão Preto (Brazil), from 1990 to 1997, adopting the modified Trial of ORG 10172 in Acute Stroke Treatment (TOAST) criteria of classification; 1 - Atherosclerosis in large arteries; 2 - Cardioembolic; 3 - Occlusion of small vessels; 4 - Other etiologies; 5 - Undetermined cause. Thirty-nine children were included, 18 males and 21 females, aged 2 months to 15 years, mean age 5.67. The largest group, $\mathrm{N}=22(56.4 \%)$, included children with "other etiologies", 7 of them aged under two years. The most common etiology was dehydration and septic shock leading to brain hypoperfusion and watershed infarcts. Nine (23\%) children had "Undetermined etiology", 7 (17,9\%) cardioembolic subtype and none had atherosclerosis. Laboratory improvement is needed for the large number of patients without a defined cause, and the high proportion of children with dehydration in the group with a determined cause emphasizes the need for preventive health actions among infants and children.
\end{abstract}

KEY WORDS: cerebrovascular disease, cerebral infarct, stroke, children, infants, etiology.

\begin{abstract}
Infarto cerebral em crianças de zero a quinze anos de idade
RESUMO - Infartos cerebrais em crianças apresentam peculiaridades, como grande variedade de causas e alta freqüência sem etiologia definida. Foram revistos os diagnósticos etiológicos em crianças de zero a 15 anos, atendidas durante o ictus e com imagens cerebrais sugestivas de infarto, entre 1990 e 1997 em hospital terciário de Ribeirão Preto (SP). Adotou-se o critério de classificação modificado do Trial of ORG 10172 in Acute Stroke Treatment (TOAST): 1 - Arterioesclerose de grandes artérias, 2 - Cardioembólico, 3 - Oclusão de pequenos vasos, 4 - Outras etiologias, 5 - Não determinada. Trinta e nove crianças foram incluídas, 18 do sexo masculino e 21 do feminino, com idade variando entre 2 meses e 15 anos e média de 5,67 . O maior grupo, com 22 crianças $(56,4 \%)$, foi o de "Outras etiologias", 7 das quais com idades entre 2 meses e um ano. A etiologia mais freqüente foi desidratação e choque séptico, levando a hipoperfusão cerebral e infarto em zonas limítrofes. Nove (23\%) com etiologia não determinada constituiram o segundo grupo, $7(17,9 \%)$ apresentaram causas cardioembólicas e nenhum caso foi registrado com arteriosclerose. Ressalta-se a necessidade de investimento laboratorial, considerando-se a alta freqüência de casos sem diagnóstico. $O$ alto número de crianças com infarto decorrente de desidratação requer atenção para ações preventivas em saúde infantil.
\end{abstract}

PALAVRAS-CHAVE: doença vascular cerebral, infarto cerebral, criança, lactente, etiologia.

In studies about cerebral infarcts in children, despite many different methodologic approach, a common observation is the wide diversity of etiologies. According to the Pan American Health Organization, in the last decade the mortality rate for Brazilian children under one year was 6 times higher than the rates reported by developed countries ${ }^{1}$. We hypothesized that the high morbidity condition of the disease in Brazil is a consequence of distinctive characteristics in the distribution of the causes of cerebral infarcts.

Thus, the objective of the present investigation was to identify cerebral infarcts in children aged zero to 15 years attended at a tertiary hospital,

\footnotetext{
${ }^{1}$ Faculdade de Medicina de Ribeirão Preto da Universidade de São Paulo (FMRP/USP) Ribeirão Preto SP, Brasil; ${ }^{2}$ Faculdade de Medicina da Universidade Federal do Ceará, Fortaleza CE, Brasil.
}

Received 6 June 2003, received in final form 28 August 2003. Accepted 6 October 2003. 
studying the specific distribution of etiological groups according to age and reviewing some aspects of each etiology identified.

\section{METHOD}

After approval by the Research Ethics Committee of the University Hospital of Ribeirão Preto, the medical records of all patients aged zero to 15 years with cerebral infarct, from 1990 to 1997, were reviewed. Those with a focal ictal history and vascular etiology confirmed by cerebral imaging were included. Children with perinatal or post-natal hypoxic-ischemic encephalopathy were excluded. The age limit of 15 years was considered according to Williams et al. ${ }^{2}$, who stated that infarcts at 15 to 18 years of age are similar to those of adults.

The sample was divided in groups according to the modified criteria of the TOAST ${ }^{3}$, which classifies cere-

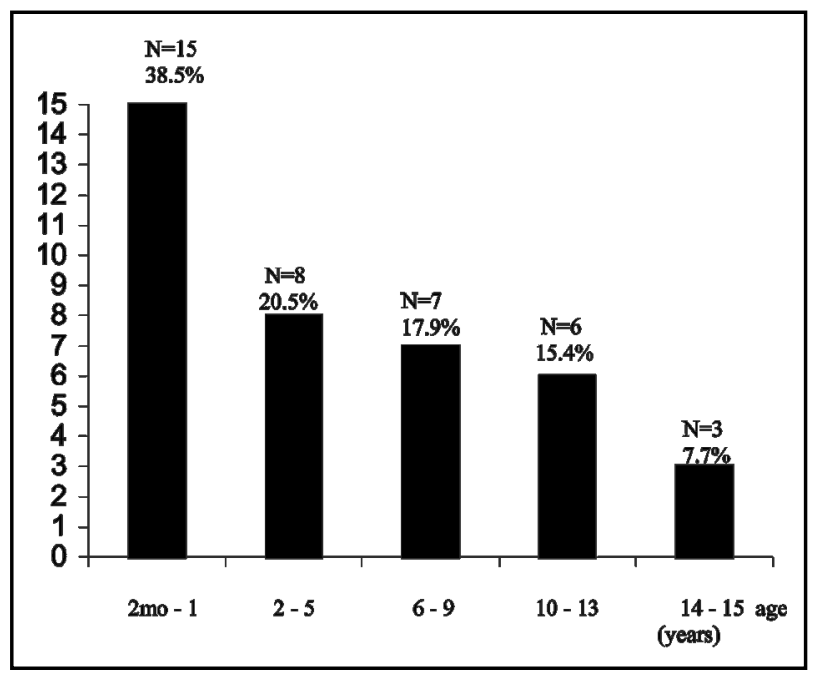

Fig 1. Number of cases according to age. bral infarcts as: (1) atherosclerosis of the large arteries, (2) cardioembolic (3) occlusion of small vessels or lacunae, (4) other etiologies, and (5) undetermined cause.

\section{RESULTS}

Thirty-nine patients were included, 18 (46.2\%) males and 21 (53.8\%) females. Mean age was 5.67 \pm 5.02 years (range: 2 months to 15 years) (Fig. 1 ).

The causes of cerebral infarcts are listed in Table 1 and Fig. 2.

No child presented atherosclerosis.

Of the $7(17,9 \%)$ children with cardioembolic infarcts, one had Down's syndrome and presented congenital cardiopathy of the complete atrioventricular septal defect type. Two with a metal prosthesis had rheumatic disease. Prolapse of the mitral valve was considered to be the cause in one adolescent patient with extensive fruitless investigation, and in view of the angiographic evidence of occlusion with subsequent flow reestablishment.

One diabetic child, age 8, presented classic microangiopathic lacunar syndrome and signs of capsular lacunar lesion (smaller than $1.5 \mathrm{~cm}$ ) on resonance imaging.

Of the $22(56,4 \%)$ patients with infarct caused by other etiologies, 8 presented the cerebral infarct during the course of dehydration due to acute diarrhea, evolving to septic shock; 7 of them aged below 2 years. Six had multiple bilateral border zone lesions, and 2 had a single unilateral cortical lesion, one of them anterior and the other in the vertebral-basilar territory.

Three with moyamoya disease were females, one of them with Down's syndrome.

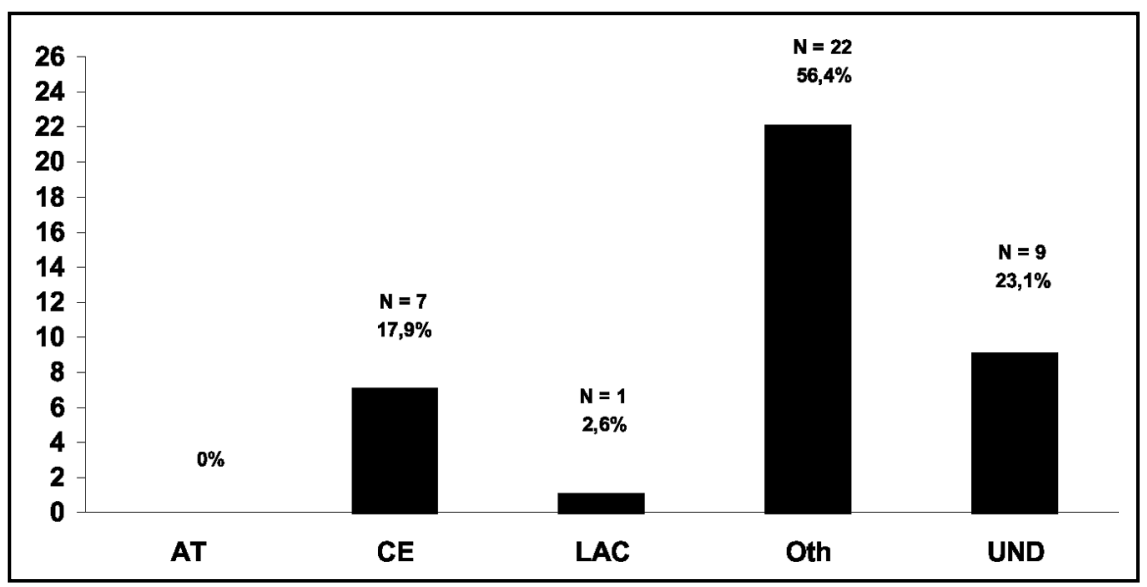

Fig 2. Etiologies of the infarcts. AT, atherosclerosis of large arteries; $C E$, cardioembolic; LAC, occlusion of small vessels or lacunar infarcts; Oth, other etiologies; UND, infarcts with undetermined causes. 
Table 1. Etiologies of cerebral infarct in 39 children.

\begin{tabular}{lc}
\hline Etiology & $\mathrm{n}(\%)$ \\
\hline Cardioembolic & $7(17.9 \%)$ \\
Rheumatic disease & 2 \\
Infectious endocarditis & 2 \\
Congenital heart disease & 1 \\
Endomyocardiofibrosis & 1 \\
Mitral valve prolapse & 1 \\
Small vessel occlusion & $1(2.6 \%)$ \\
Diabetes mellitus & 1 \\
Other, determined causes & $22(56.4 \%)$ \\
Hemodynamic infarct & 8 \\
Moya-moya & 3 \\
Sickle cell disease & 3 \\
Varicella & 2 \\
Upper respiratory infection & 1 \\
Hemolytic uremic syndrome & 1 \\
Central venous thrombosis (CVT) & 3 \\
Antiphospholipid antibody syndrome/CVT & 1 \\
Unknown & $9(23.1 \%)$ \\
Total & $39(100 \%)$ \\
\hline
\end{tabular}

In two children the cerebral infarct respectively occurred in the acute phase of chicken pox and 50 days the disease. Both presented subcortical infarcts of lacunar dimensions and normal venous studies.

Sickle cell disease was the cause of multiple bilateral border-zone infarct of the middle and anterior arteries in 3 patients aged 1, 3 and 7 years, two of them with recurrence.

One patient aged 18 months presented sudden hemiparesis on the forth day of an upper respiratory infection. Amino acid analysis, determination of $C$ and $S$ proteins and antithrombin III, cerebral angiography and echocardiography were normal. Magnetic resonance imaging showed signs of infarct smaller than $1.5 \mathrm{~cm}$ in the lenticulostriate territory.

Hemolytic uremic syndrome was detected in another patient aged 45 months, whose cerebral computed tomography demonstrated widespread diffuse hypodensity of white matter associated with a small sign of lesion in the head of right caudate nucleus, later evolving with resolution of hypodensity and greater delimitation of a lacunar infarct.

The etiologies of three cases that presented central venous thrombosis (CVT) were: dehydration, otitis associated with a history of undefined hypercoagulability and acute lymphatic leukemia, with the detection of empty delta signs in all of them. In another patient with CVT at the age of 1 year and 4 months, antiphospholipid antibody syndrome was diagnosed, since this patient presented recurrent and persistently altered doses of anticardiolipin antibody. This patient presented slightly reduced protein $S$ levels.

The cause of the infarct was not determined in nine patients $(23 \%)$, although seven of them showed abnormal signs upon angiography.

\section{DISCUSSION}

Children can present stroke at any age. The incidence is higher under the age of 2 years and progressively decreases throughout adolescence ${ }^{4-7}$. This trend was also identified in our study. Although we found a slight predominance of female patients, the literature on the topic does not demonstrate statistically significant differences ${ }^{2,4-7}$. We did not find newborn infants in the present series, probably due to difficulties in performing imaging exams during the acute phase of the disease at this time during the investigation. In newborn infants, when peri-intraventricular hemorrhages are excluded, cerebrovascular disease more frequently presents convulsive seizures as the initial manifestation ${ }^{8,9}$.

A system for categorization of cerebral infarct subtypes based principally on the etiology of infarcts was developed by $\mathrm{TOAST}^{3}$, and is currently the most frequently adopted classification for adults. Williams et al. ${ }^{2}$ were the first to use TOAST criteria in children series. Analysis of the distribution of our patients demonstrated a predominance of infarcts caused by other etiologies, followed by cardioembolic cases and those with an undetermined cause.

No patient had stroke secondary to atherosoclerosis of the large arteries. Our results are in line with the major series involving populations in the same age range $e^{2,5-7,9,10}$. The prevalence of infarcts resulting from atherosclerosis of the large arteries increases with age ${ }^{2}$. Infarcts of this type are particularly common among the elderly, but represent, along with lacunar infarcts, less than $30 \%$ of infarcts in people aged under 50 years ${ }^{11}$.

Patients with occlusion of large arteries due to atherosclerosis have various well established associated risk factors such as hypertension, diabetes, smoking, ethylism and hyperlipidemia, which are 
not usually found in the pediatric group 4 . In the Williams et al. ${ }^{2}$ series, among 92 patients aged 1 to 18 years no case was recorded, but $16 \%$ of 116 were 18 to 45 years old. Siqueira ${ }^{11}$ found $2.6 \%$ of patients in the 15 to 29 year range and $11.8 \%$ in the 30 to 45 year range.

Only one patient of school age who suffered from diabetes mellitus presented lacunar infarcts in our study. This reduced frequency is in line with most of the series in the literature, where no or few cases were identified ${ }^{2,5,6,8}$. Risk factors such as chronic hypertension, atherosclerosis or diabetes mellitus, which are important in adults, are rarely present in children with lacunar infarcts, an age at which such lesions usually originate from embolic events or arteritis ${ }^{12}$.

Cardioembolic infarcts were responsible for $18 \%$ of our cases. In the major series, the prevalence of cardioembolic infarcts varied from 3 to $65 \% 2,5,6,7$. This wide range in the prevalence of infarcts was attributed to the differences in the methodologies used in each study. According to some authors, congenital ${ }^{13,14}$ and acquired cardiopathies ${ }^{12-17}$ are the most common causes of cardioembolic infarcts in children, with a special emphasis on complex cardiopathies ${ }^{15-17}$. Emboli from the heart or from right - left shunt by paradoxical embolisms constitute usual mechanisms of cerebral embolism in these patients. Cerebral infarcts in association with congenital cardiopathy occur more frequently in children aged under 2 years $^{14}$.

The only patient we detected with congenital cardiopathy had Down's syndrome, with A - V shunt, a common congenital cardiac alteration for this chromosomal anomaly.

Two patients $(28.6 \%)$ with cardioembolism presented bacterial endocarditis. Congenital or acquired valvar stenoses is usually responsible for the production of bacterial or aseptic growth ${ }^{16}$. These defects were not present in either of our two cases. The mechanisms involved in the cerebral infarct are septic embolization, formation of aneurysm and vasculitis and beside the increase of the power and spectrum of antibiotics, 15 to $20 \%$ of patients with endocarditis still develop a cerebral infarct ${ }^{17}$.

The relation between mitral valve prolapse (MVP) and strokes is controversial. The prevalence of MVP in the general population is around 5 to $15 \%$. We did not find any specific information regarding the risk and prevalence of MVP in the pediatric population, although it is believed to be minimal ${ }^{16}$. In the TOAST classification, MVP was considered a source of cardioembolism with a medium risk ${ }^{3}$. The current belief is that MVP should only be implied in the etiology of infarcts in the presence of a pathologic MVP, according to strict criteria of morphologic alterations of the valves and if the extensive search for other etiologies provides no results ${ }^{17}$. Our patient with MVP presented ictus during puberty and other possible causes were excluded after an extensive investigation. Furthermore, the angiography strongly suggested an embolic process demonstrating occlusion and subsequent reestablishment of the arterial flow.

Synthetic valve prostheses represent high risk of thromboembolism, particularly cerebral embolism, which is still one of the most devastating complicating factors in the appearance of this disease. The annual risk is estimated at $4 \%$ for mitral prostheses and $2 \%$ for prostheses located in the aorta ${ }^{17,19}$. In our patient, mechanic prostheses represented $28.6 \%$ of the sources of cardioembolism.

"Other etiologies" accounted for $56.4 \%$ of our sample, slightly superior to Williams et al. $49 \%^{2}$ and lower than the more recent series of Wraige et al, $80 \%^{20}$. Systemic hypoperfusion accounted for the highest number of cases in our sample, corresponding to $20.5 \%$ of the total. These infarcts occur when there is a critical reduction in the blood supply, insufficient to maintain the integrity of the nerve tissue.

The concept of hemodynamic disorders of cerebral perfusion as a cause of infarcts is not recent $^{21}$, although it has been seldom covered or discussed in major case studies. All the factors that promote a reduction in the volemia or global circulatory insufficiency could be implied. It represents 8 to $10 \%$ of ischemic cerebrovascular lesions, even though autopsy studies consider this number underestimated ${ }^{21,22}$. Of our 8 patients with systemic hypoperfusion cerebral infarction, $7(87.5 \%)$ aged below 2 years. This higher incidence in this age could be attributed to clinical conditions of a low social-economic level population, as it is still an easy target for infectious diarrheas with severe dehydration. Two other Brazilian studies ${ }^{7,9}$ did not repport this etiology and 
found hematologic and cardiac diseases as main cause of cerebrovascular disease.

Moyamoya disease is an angiographic pattern similar to smoke puff associated with progressive arterial occlusion and colaterals telangiectasias distal to the occlusion. It has been reported in $8 \%^{2}$ to $14 \%^{23}$ of the cases. Our 3 patients were females and two were diagnosed during the first decade of life. The literature emphasizes the predominance of the disease in females and the bimodal age distribution, with peaks of incidence under 10 and between 30 and 40 years ${ }^{23,24}$. Franco et al..$^{25}$ provided an excellent review of the disease and reported 3 cases involving young males, with the youngest being 14 years old.

Sickle cell anemia corresponded to $7.7 \%$ of our sample, lower than $12.6 \%^{24}$ or $19.5 \%^{2}$ reported in series from the United States, where $0.15 \%$ of the black population is SS homozygous. Many of the ischemic lesions in sickle cell patients are clinically silent and are revealed only by neuroimaging ${ }^{26}$. The first ictus occurs mainly between

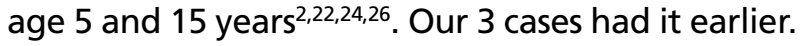

Among the studies on cerebral infarct associated with varicella-zoster, the great majority involved ophthalmic herpes zoster 27,28 . Varicella was responsible for $2(5.1 \%)$ of our 39 cases. Higgins et al. ${ }^{24}$ detected only 1 case of varicella in their study of 95 patients aged 1 month to 22 years. It has been suggested that infarcts are late complications of varicella, occurring 3 weeks to 6 months after the infection ${ }^{4}$, and intrathecal production of antibodies to varicella zoster has been detected up to four years after the primary infection in children with stroke and cerebrovascular disea$\mathrm{se}^{29}$. However, there are reports of acute hemiparesis as early as during the first week of infection $^{28}$, as was recorded in one of our patients.

Respiratory infections have been related to stroke ever since the dawning of the medical literature and still generate reports of sporadic cases $^{14,30-32}$. Although in many of these patients the infecting organism is not identified, many viral infections attributed to the Influenza $A$, Coxsackie B4 and Coxsackie A9 viruses have been documented ${ }^{31,32}$. The physiopathology of the event was not well established. The inflammatory mechanisms are hypothetically capable of stimulating coagulation by different means, including alteration of lysis and platelet aggregation, or inhibition of the anticoagulant system by a reduction of $\mathrm{C}$ and $\mathrm{S}$ protein levels and an increase in fibrinogen, among others ${ }^{30-32}$. All of these factors suggest a possible association between cerebral infarcts, infection and prothrombotic conditions. In our patient we found normal $C$ and $S$ proteins and antithrombin III. Since a highly evident temporal relation occurred between the ictus event and upper respiratory infection, and since we discarded all the other etiologies, we considered this association.

Hemolytic uremic syndrome is characterized by the triad microangiopathic hemolytic anemia, uremia and thrombocytopenia ${ }^{33}$. The basic lesion consists of endothelial vascular damage, especially renal, although other organs may be affected. Neurological malfunctions occur in 30 to $50 \%$ of the cases, and when present are related to a less optimistic prognosis ${ }^{33}$. Our patient presented a good neurological evolution.

We detected $3(7.7 \%)$ patients with CVT, all of them presenting prothrombotic conditions such as acute intense dehydration, acute lymphatic leukemia and acute otitis media with hypercoagulability state. Although the empty delta signal was viewed in all patients, the signal has a low general rate of detection in approximately $30 \%$ of ca$\mathrm{ses}^{34}$. It is attributed to two main factors: either thrombosis does not involve the upper third section of the upper sagittal sinus, or when the tests are performed very early, during the first five days, when the clots are isodense with the parenchyma, or very late, after two months, when the sinus flow has already been reestablished ${ }^{34}$.

We diagnosed one case of antiphospholipid antibody syndrome during the investigation of a CVT episode in a nursing male infant who did not demonstrate clinical or laboratory factors associated with other prior or concomitant diseases, raising the total CVT in the case study to $4(10.2 \%)$, i.e., $18.2 \%$ of infarcts caused by other etiologies. Antiphospholipid antibody syndrome presents clinical and laboratory manifestations of recurrent arterial and/or venous thrombosis, recurrent abortions and thrombocytopenia ${ }^{35}$, besides autoimmune hemolytic anemia and cardiac, cutaneous and neurological alterations ${ }^{36}$.

The group without identified etiology was the second most numerous in our series, accounting for $23 \%$ of cases. Recent progress in the recognition of the etiologies of cerebral infarct in children $^{20,37}$ has reduced the proportion of 25- 


\section{$47.6 \% 4,7,12$ of undetermined causes to values such as $8.3 \%^{20}$.}

In conclusion, in agreement with the literature, the present sample of Brazilian children presented a wide diversity of etiologies for cerebral infarcts, and therefore required more extensive investigation. We emphasized the importance of severe dehydration related to border zone infarcts in the group aged under two, as well as the importance of preventive strategies in infantile health. In addition, we call attention to the need for progress in laboratory diagnosis in view of the high number of cases of undetermined etiology.

\section{REFERENCES}

1. OPAS. Organización Panamericana de la Salud. Estatisticas de la salud de las Americas. Washington: OPAS, OMS, 1997.

2. Williams LS, Garg BP, Cohen M, Fleck JD, Biller J. Subtypes of ischemic stroke in children and young adults. Neurology 1997;49:1541-1545.

3. Adams HP Jr, Bendixen BH, Kappelle LJ, et al. Classification of subtype of acute ischemic stroke, definitions for use in a multicenter clinical trial. Stroke 1993;24:35-41.

4. Mathews KD. Stroke in neonates and children: overview. In Biller J Mathews KD, Love BB, (eds). Stroke in children and young adults. Boston: Butterworth - Heinemann, 1994:15-30.

5. Lanska MJ, Lanska DJ, Horwitz SJ, Aram, DM. Presentation, clinica course, and outcome of childhood stroke. Pediat Neurol 1991;7:333-341.

6. Schoenberg BS, Mellinger JF, Schoenberg DG. Cerebrovascular disease in infants and children: a study of incidence, clinical features, and survival. Neurology 1978;28:763-768.

7. Moura-Ribeiro MVL, Ferreira LS, Montenegro MA, et al. Doença cerebrovascular na infância. Arq Neuropsiquiatr 1999;57:594-598.

8. Moura-Ribeiro MVL, Pessoto MA, Marba STM. Cerebrovascular disease in neonates. Arq Neuropsiquiatr 1999;57:84-87.

9. Rotta NT, Silva AR, Silva FLF, et al. Cerebrovascular disease in pediatric patients. Arq Neuropsiquiatr 2002;60:959-963.

10. Kirkham FJ. Stroke in childhood. Arch Dis Child 1999;81:85-89.

11. Siqueira JI Neto, Santos AC, Fabio SRC, Sakamoto AC. Cerebral infarction in patients aged 15 to 40 years. Stroke 1996;27:2016-2019.

12. Roach ES. Cerebrovascular disease in young patients. American Academy of Neurology. Annual Meeting: Seattle 1995:53-78.

13. Lasjaunias $\mathrm{P}$, Brugge $\mathrm{K}$. Arterial ischaemic stroke. In Lasjaunias P (ed). Vascular diseases in neonates, infants and children. Berlin: Springer - Verlag, 1997:393-418.

14. Trescher WH. Ischemic stroke syndromes in childhood. Ann Pediat 1992;21:374-383.

15. Roach ES, Riela AR. Introduction and overview. In Roach ES, Riela AR (eds). Pediatric cerebrovascular disorders. New York: Futura 1995:1-12.
16. Roach ES, Riela AR. Cerebral embolism. In Roach ES, Riela AR (eds). Pediatric cerebrovascular disorders. New York: Futura, 1995:51-68.

17. Streifler JY, Furlen AJ, Barnett HJM. Cardiogenic brain embolism incidence, varieties, treatment. In Barnett HJM, Mohr JP, Stein BM, Yatsu FM (eds). Stroke: pathophysiology, diagnosis and management. New York: Churchill Livingstone, 1992:967-994.

18. Wolf PA, Sila CA. Cerebral ischemia with mitral valve prolapse. Am Heart J 1987;113:1308-1315.

19. Cerebral Embolism Task Force. Cardiogenic brain embolism. Arch Neurol 1986;43:71-84

20. Wraige E, Hajat C, Jan W, Pohl KR, Wolfe CD, Ganesan V. Ischaemic stroke subtypes in children and adults. Dev Med Child Neurol 2003; 45:229-232.

21. Bladin CF, Chambers BR. Frequency and pathogenesis of hemodynamic stroke. Stroke 1994;25:2179-2182.

22. Biller J. Non-atherosclerotic vasculopathies. In Biller J, Mathews KD, Love BB (eds). Stroke in children and young adults. Boston: Butterwoth - Heinemann, 1994:57-82.

23. Yonekawa Y, Goto Y, Ogata N. Moyamoya disease: diagnosis, treatment, and recent achievement. In Barnett HJM, Stein BM, Mohr JP Yatsu FM (eds). Stroke-pathophysiology, diagnosis and management. New York: Churchill Livingstone, 1992:721-748.

24. Higgins JJ, Kammerman LA, Fitz KC. Predictors of survival and characteristics of childhood stroke. Neuropediatrics 1990;22:190-193.

25. Franco CMR, Fukujima MM, Oliveira RMC, Gabai AA, Moyamoya disease. Arq Neuropsiquiatr 1999;57:371-376.

26. Riela AR, Roach S. Etiology of stroke in children. J Child Neurol 1993;8:201-220.

27. Takeoka M, Takahashi T. Infectious and inflammatory disorders of the circulatory system and stroke in childhood . Curr Opin Neurol 2002;15:159-164.

28. Ganesan V, Kirkham FJ. Mechanism of ischaemic stroke after chickenpox. Arch Dis Child 1997;76:522-525.

29. Häusler MG, Ramaekers VTh, Reul J, Meilicke R, Heimann G. Early and late onset manifestations of cerebral vasculitis related to varicella zoster. Neuropediatrics 1998;29:202-207.

30. Grau AJ, Buggle F, Heindl S, et al. Recent infection as a risk factor for cerebrovascular ischemia. Stroke 1995;26:373-379.

31. Roach ES, Riela AR. Inflamatory vascular disorders. In Roach ES Riela AR (eds). Pediatric cerebrovascular disorders. New York: Futura, 1995:121-140.

32. Zilkha A, Mendelsohn F, Borofsky LG. Acute hemiplegia in children complicating upper respiratory infections. Clin Pediatr 1976;15:11371142.

33. Sheth KJ, Swick HM, Haworth N. Neurological involvement in hemolytic-uremic syndrome. Ann Neurol 1986;19:90-93.

34. Virapongse C, Cazenave C, Quisling R, Sarwar M, Hunter S. The empty delta sign: frequency and significance in 76 cases of dural sinus thrombosis. Radiology 1987;162:779-785.

35. Louzada P Jr, Simon SM, Voltarelli JC, Donadi EA. Síndrome do anticorpo antifosfolípide. Medicina (Ribeirão Preto) 1998;31:305-315.

36. Kenet G, Sadetzki S, Murad H, et al. Factor V Leiden and antiphospholipid antibodies are significant risk factors for ischemic stroke in children. Stroke 2000,31:1283-1288.

37. Cardo E, Vilaseca MA, Campistol J, Artuch R, Colome C, Pineda M Evaluation of hyperhomocysteinaemia in children with stroke. Eur J Paediatr Neurol 1999:3:113-117. 